University of Zurich

Department of Economics

Working Paper Series

ISSN 1664-7041 (print)

ISSN1664-705X(online)

Working Paper No. 27

\title{
Big experimenter is watching you! Anonymity and prosocial behavior in the laboratory
}

Franziska Barmettler, Ernst Fehr and Christian Zehnder

August 2011 


\title{
Big experimenter is watching you! Anonymity and prosocial behavior in the laboratory
}

\author{
Franziska Barmettler*, Ernst Fehr†, and Christian Zehnder ${ }^{\ddagger}$
}

July 2011

\begin{abstract}
Social preference research has received considerable attention in recent years. Researchers have demonstrated that the presence of people with other-regarding preferences can have important implications in many economic dimensions. However, it is important to be aware of the fact that the empirical basis of this literature relies to a large extent on experiments that do not provide anonymity between experimenter and subject. It has been argued that this lack of experimenter-subject anonymity may create selfish incentives to engage in seemingly other-regarding behavior. If this were the case these experiments would overestimate the importance of social preferences. Previous studies provide mixed results and methodological differences within and across studies make it difficult to isolate the impact of experimenter-subject anonymity on prosocial behavior. In this paper we use a novel procedure that allows us to examine the impact of the exact same ceteris-paribus variation in anonymity on behavior in three of the most commonly used games in the social preference literature. Our data reveals that introducing experimenter-subject anonymity has only minor, insignificant, effects on prosocial behavior.
\end{abstract}

Keywords: scrutiny, anonymity, laboratory experiments, prosocial behavior

JEL: C91, D03

\footnotetext{
*Foundation for Global Sustainability (FFGS), Minervastrasse 99 CH-8032 Zurich (e-mail: franziska.barmettler@ffgs.org).

${ }^{\dagger}$ University of Zurich, Department of Economics, Bluemlisalpstr. 10, CH-8006 Zurich (e-mail: ernst.fehr@econ.uzh.ch).

${ }^{\ddagger}$ Corresponding author. University of Lausanne, Faculty of Business and Economics, Quartier UNIL-Dorigny, Internef 612, CH-1015 Lausanne (e-mail: christian.zehnder@unil.ch).
} 


\section{Introduction}

Most laboratory experiments in economics lack experimenter-subject anonymity, i.e., the experimenter can link individual decisions to the identity of the subject. In this paper we investigate whether the absence of experimenter-subject anonymity leads to a systematic overstatement of the importance of social preferences. To this end we develop novel experimental procedures that allow us to implement a clean ceterisparibus manipulation of experimenter-subject anonymity. We apply our procedure to three of the most frequently used experimental games in the literature on social preferences: the dictator game, the ultimatum game, and the trust game. We find that inducing experimenter-subject anonymity does not significantly affect the observed extent of prosocial behavior in any of our three games.

To clarify the relevance of our results it is useful to start with some background and motivation. Over the last two decades social preference research has developed into one of the largest programs in behavioral economics (see, e.g., Fehr and Schmidt, 2003; Camerer, 2003; Cooper and Kagel, forthcoming, for extensive reviews of the literature). Researchers have succeeded in integrating social preferences in game theoretic models ${ }^{1}$ and laboratory and field studies show that the presence of a significant fraction of people with non-selfish preferences has crucial implications for various important dimensions of economic activity. Examples comprise tax policies and public economics in general (Bowles and Hwang, 2008; Ackert et al., 2009; Tyran and Sausgruber, 2006), contract enforcement (Fehr et al., 1997; Charness and Dufwenberg, 2006), wage formation and relational contracting (Brown et al., 2004; Falk et al., 2006), public goods provision (Andreoni, 1990, 1995; Fehr and Gaechter, 2000; Masclet and Villeval, 2008), or organizational economics (MacLeod and Malcomson, 1998; MacLeod, 2007; Ellingsen and Johannesson, 2008; Fehr et al., 2011).

In light of the far reaching economic implications and policy consequences of social preferences it is important to emphasize that the empirical foundation of this literature is based to a large extent on laboratory experiments. This has raised the concern that the effects of social preferences identified in the laboratory may not carry over to the field. Recently, this problem has been the subject of an intensive methodological debate about the role of laboratory experiments in economic research (see, e.g., Levitt and List, 2007; Falk and Heckman, 2009; List, 2009; Bardsley et al., 2010; Croson and Gaechter,

\footnotetext{
${ }^{1}$ Social preferences have been formalized in terms of inequity aversion (Fehr and Schmidt, 1999; Bolton and Ockenfels, 2000), fairness intention (Rabin, 1993; Dufwenberg and Kirchsteiger, 2004; Falk and Fischbacher, 2006), type-based reciprocity (Levine, 1998), preferences for social welfare (Charness and Rabin, 2002), and concerns for social reputation or self-respect (Benabou and Tirole, 2006; Ellingsen and Johannesson, 2007). These theories proved to be helpful in organizing the data and have been applied to many important economic questions such as contract theory (Fehr et al., 2007; Bartling and von Siemens, 2010), the role of fairness in the process of institution formation (Kosfeld et al., 2009), the analysis of bargaining outcomes (Goeree and Holt, 2000), or the examination of counterproductive incentive effects (Benabou and Tirole, 2006; Ellingsen and Johannesson, 2007, 2008).
} 
2010; Henrich et al., 2010). The most prominent arguments against the generalizability of laboratory findings include concerns about low monetary stakes, self-selected student participants, short examinations periods, and high degrees of scrutiny. We believe that the best way of dealing with these issues is to rigorously investigate their empirical relevance. Of course, we are not the first ones to make such an attempt. For some aspects systematic evidence is already available. For example, there is a number of studies consistently showing that higher monetary stakes do, in general, not eliminate the role of social considerations. While there is some evidence that increasing the stakes sometimes slightly reduces the extent of other-regarding behavior (see, e.g., Slonim and Roth, 1998; Cherry et al., 2002; Carpenter et al., 2005), there is also evidence that fairness concerns still play an important role even if experimental payoffs are raised to the level of multiple monthly incomes (see, e.g., Cameron, 1999; Fehr et al., 2002). Similarly, there is also considerable evidence illustrating that using students as participants does not systematically overestimate the role of social preferences. A number of subject pool comparisons suggests that, if anything, non-students tend to exhibit even more prosocial behavior than students (see e.g., Fehr and List, 2004; Egas and Riedl, 2008; Dohmen et al., 2008; Burks et al., 2009; Belot et al., 2010). In addition, there are two recent papers that investigate selection effects and fail to find confirming evidence for the hypothesis that students with stronger prosocial inclinations are more likely to self-select into experiments (Cleave et al., 2010; Falk et al., 2010). The effect of variations in scrutiny on other-regarding behavior has also been empirically investigated in several papers before (see, in particular, Hoffman et al., 1994; Bolton and Zwick, 1995; Laury et al., 1995; Hoffman et al., 1996; Bolton et al., 1998; List et al., 2004; Cox and Deck, 2005). However, as we will discuss in much more detail in section 2 the existing studies not only provide mixed results, but differences in experimental procedures and games within and across studies make it difficult to get a coherent overall picture of the results. The novel procedure introduced in this paper aims at overcoming the problems that complicate the interpretation of these previous findings.

The reason why the lack of experimenter-subject anonymity in most economic experiments may be problematic is that the feeling of being monitored and scrutinized by the experimenter could induce subjects to change their normal behavioral patterns. In particular, if subjects care what the experimenter thinks about them - be it, for example, because they want to avoid a sense of social stigma associated with greedy behavior or because they (irrationally) believe that being greedy may lead to exclusion from future experiments - the lack of experimenter-subject anonymity may lead to exaggeration of the importance of (seemingly) prosocial behavior. To the extent to which the level of scrutiny inherent in the laboratory is higher than in the corresponding field environment, lab studies may provide a biased picture of the relevance of social preferences. For these reasons studying the effects of experimenter-subject anonymity deserves a thorough empirical examination.

When we designed our experiments, our aim was to develop experimental procedures that satisfy the following three principles: 


\section{i) Ceteris-paribus variation of experimenter-subject anonymity}

Previous studies often compare single-anonymous and double-anonymous treatments that do not only differ with respect to the presence of experimenter-subject anonymity, but also exhibit significant differences in decision making procedures (see, e.g., Hoffman et al., 1994; Bolton and Zwick, 1995; Laury et al., 1995; Bolton et al., 1998; List et al., 2004). ${ }^{2}$ This raises the problem that the additional differences in decision making procedures may lead to an underestimation or overestimation of the anonymity effect. In our experiments we make sure that the procedural details of the decision making part of the experiment are identical across treatments. The only difference between treatments is the payment procedure at the end of the experiment. However, even there everything is identical except for the fact that participants in the single-anonymous treatment need to write their name and sign a receipt which also contains their identity number. As we announce the details of the payment procedure before the experiment, this minimal but salient difference makes sure that participants in the single-anonymous treatment understand from the outset that the experimenter can link their identity number to their name. In the double-anonymous treatment instead the description of the payment procedure ensures that participants realize that the experimenter has no way to establish a link between their identity number and their name.

\section{ii) Transparent and self-explanatory experimental procedures}

Many previous studies make the subjects explicitly aware of the fact that the implemented procedures ensure experimenter-subject anonymity (see, e.g., Hoffman et al., 1994; Bolton and Zwick, 1995; Hoffman et al., 1996; Bolton et al., 1998). This may induce undesirable demand effects as the emphasis of anonymity might result in subjects inferring that the experimenter wants them to behave in a manner that might be deemed unacceptable (see, e.g., Loewenstein, 1999, for a more detailed discussion). Our experiments are designed in such a way that the explanation of the procedure itself reveals the presence or absence of experimenter-subject anonymity. A manipulation check that we performed after the experiment reveals that subjects understood the anonymity condition.

iii) Flexible procedures suitable for different games

When identifying anonymity effects previous studies concentrate on one particular game. As experimental procedures differ across studies, it is hard to determine whether variations in results across games are caused by differences in the game structure or differences in procedures. Our setup is flexible enough, so that we can use the exact same procedures in all our games. This allows us to investigate in a clean way whether anonymity effects differ across games.

We apply our procedure to three two-player games that are frequently used to mea-

\footnotetext{
${ }^{2}$ For example: In some studies actual money is placed in front of subjects in double-anonymous treatments, while decision forms or payoff-cards are used in single-anonymous treatments. Other studies put all subjects in one room in one treatments, but use several rooms in the other treatment. For more details see section 2 .
} 
sure social preferences: the dictator game, the ultimatum game, and the trust game. Overall, we have about 600 participants in our experiments, i.e., our results are based on decisions of about 100 pairs in each game. Our main findings can be summarized as follows: In the dictator game and the ultimatum game the presence of experimentersubject anonymity slightly lowers the offers made by dictators and proposers. However, in both games the effects are small and not statistically significant. ${ }^{3}$ In the trust game we do not find any effect on the trustors' behavior, while we observe that experimentersubject anonymity reduces the repayments of the trustees. But again the effect is small and not significant. ${ }^{4}$ These results suggest that the absence of experimenter-subject anonymity in laboratory experiments has only minor, insignificant, effects on subjects' behavior.

Our results are important for at least two reasons. First, our findings indicate that observed prosocial behavior in the laboratory is not just an artifact of the lack of experimenter-subject anonymity. This finding is important for the validity of many laboratory experiments that measured social preferences. Second, our findings relieve the experimenters from the burden of implementing double anonymous procedures because the behavior under single anonymous procedures provides a very good approximation of behavior under double anonymity. Ensuring experimenter-subject anonymity inevitably complicates procedures and severely limits the degrees of freedom in experimental design. In particular, in computerized experiments it is very hard to credibly guarantee complete anonymity towards the experimenter. Thus, knowing that the lack of experimenter-subject anonymity does not lead to a significant change in prosocial behavior, clears the way for many interesting future studies.

The rest of the paper is organized as follows. Section 2 discusses the previous literature on anonymity effects. In section 3 we present the details of our procedures and the design of the experiment. Section 4 reports our results and section 5 concludes.

\section{Previous Literature}

To clarify the role of our paper it is worthwhile to discuss the existing literature in some detail. For convenience of expositon, we henceforth use the term "singleanonymous" for experimental conditions without experimenter-subject anonymity and the term "double-anonymous" for conditions with experimenter-subject anonymity. ${ }^{5}$

\footnotetext{
${ }^{3}$ In the dictator game dictators transfer 16 percent of their endowment when experimenter-subject anonymity is present and 19 percent in its absence. In the ultimatum game proposers offer 42 percent of their endowment in the presence of experimenter-subject anonymity and 43 percent otherwise.

${ }^{4}$ Trustors invest 63 percent of their endowment in both treatments. Trustees' back transfers amount to 15 percent of their available funds after having received the first mover transfer when experimenter-subject anonymity prevails and 19 percent otherwise.

${ }^{5}$ Single-anonymous refers to the fact that the experiment only guarantees anonymity between subjects, while double-anonymous experiments also provide anonymity between experimenter and subject. In the previous literature some authors have used the terms "single-blind" and "double-
} 
Hoffman et al. (1994) is the first paper that investigates the impact of experimentersubject anonymity on prosocial behavior in an economic game. They compare singleanonymous and double-anonymous treatments in a one-shot dictator game with an endowment of $\$ 10$. Their data reveals a large and significant difference in dictator game outcomes across the two treatments. In the single-anonymous treatment only 18 percent of the offers were $\$ 0$ with 32 percent offering $\$ 4$ or more, while the doubleanonymous treatment resulted in 64 percent offers of $\$ 0$, with only 8 percent offering $\$ 4$ or more. 6 The authors conclude that their results indicate that "other-regarding behavior is primarily an expectations phenomenon [...] rather than the result of an autonomous private preference for equity" (Hoffman et al., 1994, page 348). However, when interpreting these results it is crucial to take into account that the two treatments compared in this study do not only differ with respect to experimenter-subject anonymity, but there are also several procedural differences that might account for a significant part of the difference. Two particularly important differences are the following: i) The verbal explanation of the game in the instructions is not identical: The single-anonymous treatment uses a phrase suggesting that the dictator and his or her counterpart "have been provisionally allocated" $\$ 10$ and the task is to "divide" the $\$ 10$. This phrase has been removed in the double-anonymous treatment. ii) The decision procedure is very different: In the single-anonymous treatment dictators fill in a form to decide about the allocation of the money. In the double-anonymous treatment they actually get the dollar bills and physically transfer the money to the recipient. It cannot be excluded that both these differences induce dictators to be more generous in the single-anonymous treatment.

In fact, follow-up experiments reported in Hoffman et al. (1996) demonstrate that the difference in behavior is much smaller when anonymity is manipulated in a way that allows to keep the procedural details constant. This cleaner comparison yields the following results: in the single-anonymous treatment 41 percent of dictators offer $\$ 0$, and 14 percent offer $\$ 4$ or more, while the double-anonymous treatment yields 50 percent offers of $\$ 0$ and 10 percent offers of $\$ 4$ and more. This difference is no longer statistically significant. ${ }^{7}$ In addition, it is also worthwhile to note that the manipulation of anonymity in this experiment was rather extreme. In the doubleanonymous treatment each dictator received an envelope with 10 one-dollar bills and 10 paper slips. Each dictator had to take 10 items out of the envelope (any combination of paper money and paper slips) and return the sealed envelope with the remaining 10 items to a box before leaving the experiment. In the single-anonymous treatment each dictator had to bring his unsealed envelope to the experimenter who inspected the content behind a cardboard wall. This personal and explicit revelation of the subject's

\footnotetext{
blind" to make the same distinction. However, this terminology may cause misunderstandings as in other scientific disciplines the term "double-blind" is typically used to describe a setup in which neither the researcher nor the subject knows which treatment the subject received (e.g., placebo or medication in clinical studies).

${ }^{6}$ These numbers refer to the FHSS R vs. DB1 comparison, see Hoffman et al. (1996) for details.

${ }^{7}$ These numbers refer to the SB1 vs. DB2 comparison, see Hoffman et al. (1996) for details.
} 
choice to the experimenter is rather unusual and is likely to induce strong feelings of being scrutinized. Given these procedural peculiarities it is even more remarkable that there is no significant difference between these treatments.

Bolton et al. (1998) report evidence from two treatments that essentially replicate Hoffman et al.'s dictator game comparison. They do not find support for the hypothesis that the implementation of experimenter-subject anonymity leads to less prosocial behavior. In fact, dictators in the double-anonymous version of the game tend to give more rather than less, but the effect is not statistically significant. However, also in this study experimental procedures differ across treatments. Decisions in the single-anonymous treatment are made by selecting a card out of a set of cards with different payoff combinations. Decisions in the double-anonymous treatment are made by placing actual money in a box. Whether and how these procedural changes affect behavior is hard to tell and has not been systematically tested.

Effects of experimenter-subject anonymity in the ultimatum game have been investigated by Bolton and Zwick (1995). Using a series of 10 simplified (binary) versions of the ultimatum game they find that outcomes consistent with the self-interest equilibrium (i.e., the proposer makes a selfish offers, which is accepted by the responder) are significantly more likely in the double-anonymous version of their game (46 percent) than in the single-anonymous version (39 percent). However, the authors of the study also emphasize that "the anonymity hypothesis explains a relatively small fraction [...] of the non-equilibrium play" (Bolton and Zwick, 1995, page 111). In addition, there are again substantial differences in experimental procedures across treatments. In the double-anonymous condition participants communicate their decisions using a complex procedure which relies on selecting, sending and opening little boxes marked with geometric symbols. The procedure ensures that the experimenter has no way of linking individual decisions to specific participants. In the single-anonymous treatment the complicated box procedure is replace with a much simpler system in which participants can simply cut through cards showing geometric symbols to determine the payoffs.

Laury et al. (1995) conduct public good experiments with single- and doubleanonymous conditions using both inexperienced and experienced subjects. While experienced subjects contribute less of their endowment in the double-anonymous treatment (37 percent) than in the single-anonymous treatment (43 percent), the opposite is true for inexperienced subjects (double-anonymous: 53 percent / single-anonymous: 43 percent). However, none of these differences is statistically significant. Both treatments were computerized raising the question of whether participants believed that experimenter-subject anonymity was maintained. Being aware of this potential problem the authors distributed a brief questionnaire to experienced subjects after completing the double-anonymous experiment. All of them stated that they believed complete privacy was maintained during the experiment. The computerized decision procedures were held constant across treatments, but the seating of participants was different. In the single-anonymous treatment all participants were placed in the same room, in the double-anonymous treatment the participants were equally distributed across four 
rooms. While this ensured that members of the same group were spatially separated in the double-anonymous treatment, the additional distance itself also constitutes a difference that might have affected behavior.

List et al. (2004) examine whether the elicitation method affects responses in a contingent valuation exercise. ${ }^{8}$ Respondents in the study are asked to vote "Yes" or "No" on contributing $\$ 20$ to provide start-up capital for a new Center for Environmental Policy Analysis at the University of Central Florida. In one of their treatments responses were elicited using standard techniques which imply that the experimenter can observe each individual's response. In another treatment they used a so-called randomized response format, in which the experimenter knows the individual response ("Yes" or "No"), but does not know whether it was to the question of interest, or to an alternative innocuous question. ${ }^{9}$ The implementation of double-anonymity through the randomized response format reduces the percentage of "Yes" votes from 38 to 20. This difference is statistically significant. However, while this study convincingly illustrates that the choice of the elicitation method can significantly affect the outcome of a contingent valuation exercise, it cannot be seen as a clean ceteris-paribus variation of anonymity as usage of the randomized response format in the double-anonymous treatment implies that the decision procedure differs substantially across treatments.

The impact of additional social distance between experimenter and subjects has also been investigated for the trust game. The experiment of Cox and Deck (2005) includes a single-anonymous and a double-anonymous treatment of a computerized, binary trust game. While they do not detect any difference in first-mover behavior (in both treatments 52 percent of the first movers decide to trust), they find that second-movers in the double-anonymous treatment are significantly less likely to behave in a trustworthy manner (the percentage of trustworthy decisions is 68 in the single-anonymous treatment, but only 29 in the double-anonymous treatment). While this difference is large, it is important to notice that the comparison of second-movers relies on a quite small number of observations. The reason is that the double-anonymous treatment relies on only 27 pairs (compared to 48 pairs in the single-anonymous treatment) and only 14 of the first movers decide to trust (if the first mover does not trust, the second mover has no decision to make).

Overall, we feel that the current state of the literature makes it hard to draw conclusions about the impact of experimenter-subject anonymity on the observed degree of prosocial behavior in the lab. The evidence is mixed and differences in experimental procedures and games within and across studies hamper a clean interpretation. We hope that our study helps to clarify the picture.

\footnotetext{
${ }^{8}$ Contingent valuation methods (or stated preference methods) are typically used to obtain value measurements for nonmarketed goods or services (e.g., increased air or water quality).

${ }^{9}$ The data can be analyzed, because the researchers know the probability of getting the alternative question and the probability of responding "Yes" to the alternative question.
} 


\section{Design and Procedures}

In this section we present the design and procedures of our experiment. We begin with a short description of the three experimental games that we used to measure the prosocial behavior of our participants. Subsequently, we explain the details of our experimental protocol.

\subsection{Experimental Games}

All our games are simple two-player games that have repeatedly been used to study social preferences in the literature (see Camerer, 2003, for a survey). We have conducted strict one-shot versions of each game, i.e., each subject makes one single decision and all treatment comparisons are based on a between-subject design.

The first game that we implemented is the dictator game (Forsythe et al., 1994). In the dictator game one player (the dictator) has the possibility to allocate a given sum of money between himself and another player (the recipient). After the dictator's allocation decision, the game is over, i.e., the recipient is completely passive and does not make any decisions. In our case the dictator's endowment was 20 Swiss Francs and the transfer to the recipient could be any amount in steps of 2 Swiss Francs, i.e., 0, 2, $4, \ldots$, or 20 Francs.

The second game that we used is the ultimatum game (Gueth et al., 1982). The ultimatum game is identical to the dictator game except for the fact that the second player (the responder) can now decide whether he would like to accept or reject the offer of the first player (the proposer). Acceptance of the offer results in the payoffs implied by the proposer's allocation decision, rejection leads to payoffs of zero for both players. The endowment and the strategy set of the first mover were the same as in the dictator game.

As our third game we made use of the so called trust or investment game (Berg et al., 1995). In our version of the game both the first mover (trustor) and the second mover (trustee) receive an initial endowment of 10 Swiss Francs. The trustor can decide how much of his endowment he wants to transfer to the trustee. Whatever amount the trustor decides to transfer is tripled by the experimenter and given to the trustee. The trustee observes the decision of the trustor and then decides how much money he wants to pay back. The trustor's transfer could be any integer amount up to 10 Swiss Francs, and the trustee could repay any integer amount up to the sum of his endowment plus the tripled transfer of the first mover.

In addition to their payments from the experiment each participant also received a show-up fee of ten Swiss Francs. The subjects were informed about the show-up fee on the first page of the written instructions to the experiment. 


\subsection{Procedures}

When we planned the procedural details of our experiments our main objective was to avoid the problems that make conclusive inferences from the previous literature difficult. In particular, our aim was to design a procedure that allows for a clean ceteris-paribus variation of the experimenter-subject anonymity, is transparent and self-explanatory, and can be applied to a number of different games. As computerized experiments create a number of problems regarding experimenter-subject anonymity, we decided to run the experiment with paper and pencil. ${ }^{10}$ All experiments were carried out in a large lecture room with about 300 seats. To guarantee privacy we restricted the recruitment to 30 participants per session. In total we conducted 26 sessions with 602 participants. All experiments were conducted by one experimenter (Franziska Barmettler) and three assistants.

In the following we describe in much detail the procedures that we applied in all our sessions. Steps 1 to 3 were identical in single- and double-anonymous treatments. The only difference is in Step 4 (the payout system).

\section{Step 1: Random determination of role in games}

After the experimenter and assistant 1 had welcomed the participants in the waiting hall in front of the lecture room, each of them had to draw an envelope out of a small opening in an nontransparent fabric bag. The bag contained three types of envelopes: red envelopes, blue envelopes and one white envelope. Subjects were informed that those people who got a colored envelope (red or blue) would participate in the experiment, while the person who got the white envelope would serve as a monitor who supervises that the experiment follows exactly the pre-designed procedures. Subjects with a red envelope were assigned to an individual workplace on the left side of the lecture room, while subjects with a blue envelope were sent to one of the workplaces on the right side of the room. All subjects were instructed not to open their envelope until they were told to do so. The subject who received the white envelope (monitor) was taken aside and received instructions from assistant 1.

\section{Step 2: Instructions}

When all subjects were seated, the experimenter instructed them to carefully read a set of written instructions which was available at the workplace. The instructions explained the payoffs structure, the experimental procedure and the payout system in great detail (an English translation of our originally German instructions is reproduced

\footnotetext{
${ }^{10}$ An obvious problem is that computerized experiments make it hard to guarantee that the computer does not record information that allows the experimenter to associate the decision with the computer or seat number of the participant. Thus, even if participants do not reveal their names at any point of the experiment, the experimenter may still have the chance to link decisions to faces. There are arguably ways to mitigate this problem (e.g., by issuing a written guarantee of the researcher or by showing the participants the code used to store the data), but all these potential solutions require that the researcher emphasizes the presence of experimenter-subject anonymity. This goes against our aim to limit the experimenter demand effect by having a self-explanatory procedure.
} 
in the appendix). At the end of the instructions the subjects were confronted with a number of control questions about the payoff structure of the experiment. After all participants had read the instructions and correctly answered the control questions, the experimental procedure were once again explained with the help of an animated slide show (the complete slide show is available on request). Possible questions about the procedure were answered in private.

\section{Step 3: Experimental Decisions}

First, subjects were told to open their red or blue envelopes and to check that the envelope contained two small cards with an identity number printed on them. The arrangement of the seating ensured that nobody but the subject could see the identity number. Then, subjects were told to put their identity cards back in the envelope. At their workplaces each first mover (red envelopes) was provided with the following items: a large yellow envelope, a small white envelope, a removable fastener, and a pen with red ink. Second movers (blue envelopes) had been provided with a small white envelope and a pen with blue ink at their workplace.

Now, the monitor distributed the decision forms (an English translation of the originally German decision form is reproduced in the appendix). First movers were asked to check the box corresponding to their decision on the form using the red ink pen. Subsequently, first movers were told to place the decision form in the yellow envelope. In addition, they were instructed to take one of their identity cards out of the red envelope, place it in the white envelope, seal the white envelope, and also insert it in the yellow envelope. Then, first movers were told to use the removable fastener to seal the yellow envelope. Once all first movers had made their decisions, the monitor came by and collected the yellow envelopes using a large cardboard box. The monitor closed the box and shuffled the envelopes by turning and shaking the box.

Next, second movers were instructed to draw one of the yellow envelopes out of the cardboard box, which the monitor brought to each individual workplace. The second movers removed the decision sheet containing the decision of the first mover (written in red ink) - while leaving the little white envelope with the identity card of the first mover in the yellow envelope - and completed the decision sheet with his or her own decision (written in blue ink). ${ }^{11}$ Then, they put the decision sheet back into the yellow envelope, added a sealed white envelope containing one of their identity cards, and sealed the yellow envelope. Finally, the monitor again collected all the yellow envelopes in the large cardboard box and handed over the box to the experimenter. The experimenter took the box, left the room, and went to an adjacent room to calculate the payoffs with help of assistants 2 and 3. At this moment the participants started to work on a post-experimental questionnaire (supervised by assistant 1 and the monitor).

Step 4: The Payout System

Up to this point the procedures in single- and double-anonymous treatments were com-

\footnotetext{
${ }^{11}$ In the dictator game there was no second movers decision. In these treatments the second movers just looked at the first mover decision before they put it back into the yellow envelope.
} 
pletely identical. The variation in anonymity was introduced in the payout system. Of course, the participants were aware of the respective payout system of their treatment when they made their decisions. The payout system was explained in detail in the written instructions and the animated slide show (see Step 1).

\section{A) Double-Anonymous Payout System}

In the double-anonymous treatments the experimenter took the decision sheets and identity cards out of the envelopes, calculated the payoffs for both players, and placed the corresponding amounts of money in stuffed envelopes labeled with the identity numbers of the players. ${ }^{12}$ Note that it is impossible for the experimenter to link a subject's decision with the subject's identity because only the subject knows his or her identity number. Moreover, because the subjects know that their identity number is private information they know that the experimenter cannot link their choices to their identity. When all payout envelopes were prepared, the experimenter placed them on a large table outside of the experiment room. Then the experimenter came back to the experiment room. Next, the monitor left the experiment room and waited at the table with the payout envelopes. The experimenter stayed with assistant 1 in the experiment room. Assistant 1 sent the participants out of the experiment room one-by-one. Each participant who arrived at the payout table took the remaining identity card out of his colored envelope and gave it to the monitor. The monitor collected the identity card and gave the participant the corresponding envelope.

This procedure ensures that nobody has the possibility to link names or faces to payoffs. The monitor was not present when payoffs were calculated. Thus, he can only link identity numbers to faces (people never mentioned their names during the experiment), but he has no information about the link between identity numbers and payoffs. The experimenter and assistants were not involved in handing over the envelopes. Thus, they can only link identity numbers to payoffs (this information is contained in the yellow envelope), but they can never link identity numbers to names or faces. To test whether participants' understood the implications of the payout procedure, the post-experimental questionnaire given to participants in the double-anonymous treatments included the question of whether it was clear from our instructions that the experimenter can never learn their personal decision. Subjects had to answer on a five point scale (ranging from $1=$ "not clear at all" to $5=$ "absolutely clear"). Out of the 308 participants in these treatments 276 participants indicated 5 (absolutely clear), 20 participants indicated 4 , and 2 participants indicated 3. This shows that the vast majority of the participants understood that the experimenter could not link their choices to their personal identities.

B) Single-Anonymous Payout System

In the single-anonymous treatments the experimenter (and assistant 2 and 3) not only stuffed the payout envelopes, but they also prepared an individual receipt for each par-

\footnotetext{
${ }^{12}$ The stuffed envelopes make it impossible to guess the amount of money in the envelope based on the thickness of the envelope.
} 
ticipant. The receipt displayed the identity number of the participant together with the earned amount of money. In these treatments only assistant 1 and the monitor stayed in the experiment room during the payout procedure, while the experimenter remained at the payout table. After the participants had handed over their identity number to the experimenter, the experimenter asked them to add their name and signature to the receipt before they received their envelope. As the participants know that the experimenter can always link decisions and identity numbers (from the information contained in the yellow envelope), the explicit link between identity number, name, and payoff on the receipt implies that the experimenter can directly link a participants identity to his or her decisions.

\section{Results}

In this section we report our results. We discuss whether and how the presence of experimenter-subject anonymity affects the behavior of participants in the dictator game, the ultimatum game and the trust game.

\subsection{Main Findings}

Overall, we had 602 participants in our experiments. Each participant participated in exactly one experimental condition. We have observations from 103 pairs in the dictator game, 100 pairs in the ultimatum game, and 98 pairs in the trust game. In each game about half of the pairs took part in a condition with experimentersubject anonymity (double-anonymity) and the other half of the pairs took part in a condition without experimenter-subject anonymity (single-anonymity). In total, we conducted 26 experimental sessions (i.e., about 23 subjects per session on average). ${ }^{13}$ Treatments (type of game and anonymity condition) were randomly allocated to the different sessions of the experiment.

We first discuss the results of the dictator game. The first two rows of Table 1 show mean and median dictator transfers in the single- and double-anonymous treatment. In addition, the table also reports the relative frequencies of dictator behavior compatible with the self-interest equilibrium (selfish) and the desire to reach an efficient equal split of payoffs (fair/trust). ${ }^{14}$ In the single-anonymous treatment the average

\footnotetext{
${ }^{13}$ The largest sessions had 28 participants. Of the 26 sessions 24 took place with at least 16 subjects. In the other two sessions low recruitment turnout and high no-show rates lead to a smaller number of participants (10 and 8 participants, respectively). The reported results are based on a data set including the two "small" sessions. However, removing these observations does not affect any of our results.

${ }^{14} \mathrm{~A}$ model based on common knowledge of pure self-interest predicts that first movers transfer CHF 0 in the dictator game and trust game and CHF 0 or CHF 2 in the ultimatum game. A desire to reach an efficient equal split implies that first mover transfers need to be equal to 10 in all three games.
} 
(median) dictator transfer amounts to CHF 3.9 (CHF 4) and we observe that 36.7 percent of dictators do not transfer any money to the recipient. In the double-anonymous treatment the average (median) dictator transfers drops to $\mathrm{CHF} 3.3$ (CHF 2) and the fraction of dictators who transfer CHF 0 increases to 42 percent. The histogram of dictator transfers displayed in Panel A of Figure 1 graphically confirms the presence of a slight tendency to make smaller dictator transfers in the presence of double anonymity. However, Table 2 reveals that the observed difference is not statistically significant. Column (1) reports a simple OLS estimation in which we regress dictator transfers on a dummy variable which takes on value 1 if the observation comes from the treatment with double-anonymity and is equal to 0 otherwise. The coefficient of the doubleanonymity variable is negative, but far from significant $(\mathrm{p}$-value $=0.373$, calculated on the basis of robust standard errors). It is also noteworthy that the transfer levels of both treatments are fully in line with the well established fact that dictators are typically willing to give 15 to 20 percent of their endowment to the recipients (see, e.g., Camerer, 2003, for a detailed review).

Second, we present the results of the ultimatum game. Rows 3 and 4 of Table 1 show that proposer behavior in the ultimatum game is remarkably stable across treatments. While the average proposer transfer is slightly lower in the double-anonymous treatment (CHF 8.3) than in the single-anonymous treatment (CHF 8.6), the medians are identical (CHF 8). Panel B of Figure 1 illustrates that also the distributions of proposer transfers in the two treatments are very similar. In both treatments we do not have a single proposer in the data set who behaves in accordance with the selfinterest prediction (i.e., no proposer transfers CHF 0 or CHF 2 in either treatment). There are two proposers who make a transfer of CHF 4 (one in each treatment), all the others transfer CHF 6 or more. In fact, as in many other ultimatum game experiments in the literature (see, e.g., Camerer, 2003, p. 48 ff., for details), the equal split (CHF 10) is the most frequently observed offer (the relative frequencies of equal-split offers are 37.7 percent (single-anonymous) and 38.3 percent (double-anonymous), see the final column of Table 1). The strong increase in proposer offers in the ultimatum game relative to dictator transfers is in line with previous findings and reflects the fact that proposers anticipate that a substantial fraction of second movers might reject low offers. The regression analysis displayed in Column (2) of Table 2 confirms that there is no significant difference in proposer behavior across the two treatments ( $\mathrm{p}$-value $=$ 0.606, calculated on the basis of robust standard errors).

We now turn to responder behavior in our ultimatum game. As we use the direct elicitation method and first mover transfers are quite high (the vast majority of proposers transfer at least 30 percent of their endowment, see Panel B of Figure 1), we do not observe many second mover rejections. In fact, only 3 of the 100 responders in our data set reject the proposer's offer (one in the single- and two in the double-anonymous treatment). Low rejection rates are not unusual in ultimatum games using the direct elicitation method (see, e.g., Camerer, 2003, p. 48-49, for a brief discussion). Existing data about rejection patterns in ultimatum games comes mostly from studies using 
the contingent response method (aka the strategy method). Needless to say that with this data no statistical test finds a significant difference in responder behavior across treatments.

Finally, we report the results of the trust game. The bottom two rows of Table 1 show that average trustor transfers are identical (CHF 6.3) across treatments, while the median transfer is even slightly higher in the double-anonymous-treatment (CHF 8 compared to CHF 7). Furthermore, the table and Panel $\mathrm{C}$ of Figure 1 also reveals that trustors in the double-anonymous treatment are somewhat more likely to transfer $\mathrm{CHF}$ 0 (selfish) and CHF 10 (full trust). However, as in the other two games the regression analysis (Column (3) of Table 2) shows that there is no statistically significant difference between first mover transfers across treatments $(\mathrm{p}=0.945$, calculated on the basis of robust standard errors).

Second mover behavior in the trust game is summarized in Panel D of Figure 1. The figure, which displays average trustee repayments conditional on trustor transfers, does not reveal obvious, systematic differences across treatments. This impression is statistically confirmed by regressing trustee repayments on a dummy for doubleanonymity and controlling for trustor transfers (Column (4) of Table 2). The regression analysis reveals that repayments tend be lower in the presence of double anonymity, but the effect is again not statistically significant $(\mathrm{p}=0.345$, calculated on the basis of robust standard errors). Furthermore, our data also replicate the common finding that positive trustor investments are, on average, just on the verge of being profitable (see, e.g., Camerer, 2003, for details). Trustors who make a positive investment gain, on average, CHF 0.35 in the single-anonymous treatment and lose, on average, CHF 0.67 in the double-anonymous treatment. Also this difference is far away from being statistically significant ( $\mathrm{p}=0.438$, calculated on the basis of robust standard errors).

To summarize: In all three games participants' behavior is fully in line with previously observed behavior in these games. The presence of double anonymity does not significantly affect behavior in any game.

\subsection{Statistical Robustness}

So far, our statistical analysis is exclusively based on simple comparisons of average transfers using OLS-estimations with robust standard errors. In the following we apply a number of additional tests to demonstrate that our results do not change, if we use methods which take potential problems of the OLS-estimator into account. First, it is well known that the presence of outliers in the data set can distort the OLS estimator and lead to unreliable results. The histograms in Figure 1 show that we have a number of outliers in our data set, in particular in the dictator and ultimatum game (e.g., some dictators/proposer transfer up to 80 percent of their endowment). In order to control for that we repeat all our estimations using robust regression. ${ }^{15}$ The results of

\footnotetext{
${ }^{15}$ See http://www.stata.com/help.cgi?rreg for technical details.
} 
these estimations are reported in columns (1) to (4) of Table 3 . While the size of some coefficients changes somewhat (e.g., in the dictator game), the non-significance of all our results is unaffected. ${ }^{16}$

Second, the experimental design implies that all our dependent variables are potentially affected by censoring. ${ }^{17}$ To account for this we present Tobit estimations in columns (5) to (8) of Table 3. Not surprisingly, using Tobit estimations mostly affects the coefficient in the regressions relating to the trust game (see columns (7) and (8)). The reason is that we have substantial fractions of trustors choosing transfers of either $\mathrm{CHF} 0$ or $\mathrm{CHF} 10$ and substantial fractions of trustees choosing repayments of $\mathrm{CHF}$ 0 in both treatments (see also Table 1 and Figure 1). However, again all treatment comparisons yield insignificant results. ${ }^{18}$

Finally, we also perform two non-parametric tests on our first mover data: the Kolmogorov-Smirnov equality-of-distributions test and the Wilcoxon rank-sum test. Both tests do not yield any significant differences between treatments in any game. ${ }^{19}$

\subsection{Discussion}

Our study reports ceteris-paribus comparisons between treatments with and without experimenter-subject anonymity for the dictator game, ultimatum game, and trust game. To put our results into perspective, we find it useful to compare our findings with the results of studies which use the same games, but manipulate another important aspect of anonymity in experiments: the subject-subject anonymity. For the dictator game there are two studies that are of particular interest in this context. First, Bohnet and Frey (1999) completely eliminate subject-subject anonymity in a dictator game. They compare a standard single-anonymous dictator game with a treatment in which matched pairs were asked to stand up and look at each other for a couple of seconds before entering the decision stage. Their results reveal that eliminating subject-subject anonymity has a large impact on dictator giving. While dictators in the baseline condition made average transfers of 26 percent of their endowment to the recipient, average transfers of dictators in the two-way identification treatment amounted to 50 percent of their endowment. This difference is highly significant $(p<0.01$, KolmogorovSmirnov test). Second, Lazear et al. (2011) push the anonymity of dictators to the extreme. They introduce a treatment, in which the recipient did not even know of the existence of a dictator at the beginning of the experiment. The recipient only learned

\footnotetext{
${ }^{16}$ The p-values corresponding to the coefficient for the double-anonymity dummy are as follows (by column): (1) $\mathrm{p}=0.244 /(2) \mathrm{p}=0.689 /(3) \mathrm{p}=0.926 /(4) \mathrm{p}=0.457$.

${ }^{17}$ The strategy set of first movers is either limited to $\{0,2,4, \ldots, 20\}$ (dictator and ultimatum game) or to $\{0,1,4, \ldots, 10\}$ (trust game) and second mover repayments in the trust game can only be in the range $\{0,1,2, \ldots, 40\}$.

${ }^{18}$ The p-values corresponding to the coefficient for the double-anonymity dummy are as follows (by column): (1) $\mathrm{p}=0.399 /(2) \mathrm{p}=0.604 /(3) \mathrm{p}=0.805 /$ (4) $\mathrm{p}=0.141$.

${ }^{19}$ The corresponding p-values are as follows (ksmirnov/ranksum): dictator game $(0.285 / 0.300) /$ ultimatum game $(1.000 / 0.700) /$ trust game $(0.997 / 0.816)$.
} 
about the dictator game if the dictator chose to enter the game. Otherwise, the dictator kept his full endowment and the recipient never got to know that the dictator would have had the opportunity to transfer money to him. The control condition is a standard single-anonymous dictator game in which everybody is informed about the game right at the beginning of the experiment. The experiment was conducted in two different locations. In one location the presence of the possibility to not enter the game lowers average dictator transfers from 19 percent of the endowment to 6 percent, and in the other location from 20 percent to 12 percent. Both decreases are statistically significant ( $p=0.02, p<0.001$; Wilcoxon rank-sum tests).

There are also ultimatum game studies which manipulate the degree of subjectsubject anonymity. Roth (1995) compares a standard ultimatum game treatment to a treatment in which participants have a chance to engage in face-to-face communication for two minutes. The communication phase took place before the subjects knew the rules of the experiment, i.e., strategic communication to directly influence the other player's behavior was not possible. They find that eliminating subject-subject anonymity through face-to-face communication increases average proposer transfers from 43 percent to 47 percent of the endowment. The fraction of offers around the equal split (i.e., 45 - 55 percent of the endowment) increased from 50 percent in the baseline treatment to 82 percent in the communication treatment. At the same time (and certainly related to the increase in offers) the rejection rate dropped from 33 percent to 6 percent. Schmidt and Zultan (2005) replicate Roth's experiment with video conferencing instead of face-to-face communication. They find that the elimination of subject-subject anonymity increases average proposer offers from 35 percent to 45 percent, while the rejection rate was reduced from 13 percent to 3 percent. Both effects are highly significant ( $p<0.01, p<0.01$; Wilcoxon rank-sum tests).

We are not aware of a study that reports a clean ceteris-paribus comparison of behavior in trust games with and without subject-subject anonymity, but Glaeser et al. (2000) conduct a trust game in which the subjects meet the person with whom they are matched before the game is played. The experiment is based on the design of Berg et al. (1995). However, since the author were worried that the absence of subject-subject anonymity would increase cooperation in the trust game so strongly that variation in trusting behavior would be eliminated, they reduced the incentive to cooperate by only doubling rather than tripling the money sent by the trustor. Despite the reduced investment incentive Glaeser et al. (2000) find that trustors invest 83 percent of their endowment, while trustors in Berg et al. (1995) only transfer about 50 percent of their endowment. In addition, while trustees repayments in Glaeser et al. (2000) amount to about 45 percent of their available funds, trustees in Berg et al. (1995) repay only about 32 percent of their available funds. ${ }^{20}$

\footnotetext{
${ }^{20}$ This implies that the level of repayments was almost identical in the two experiments despite the difference in the multiplier of trustor investments. In Glaeser et al. (2000) trustees repay on average about 90 percent of the trustor investment, in Berg et al. (1995) they repay about 95 percent of the investment.
} 
These results indicate that anonymity with respect to other subjects has an important influence on decisions in all three games. More anonymity leads to substantial decreases in the amount transferred by first movers in all three games and there is also a significant impact on second mover behavior in the ultimatum game and the trust game. Relative to these findings our results reveal that anonymity with respect to the experimenter is of much lower importance. Introducing experimenter-subject anonymity decreases average dictator transfers from 19 percent of the endowment to 16 percent, decreases average proposer transfers from 43 percent of the endowment to 42 percent, does not affect average trustor investments, and decreases average trustee repayments from 19 percent of their available funds to 15 percent. In comparison to the changes induced by manipulations of subject-subject anonymity described above all these effects are small and none of them reaches a conventional level of significance.

\section{Conclusions}

The existing evidence on the impact of experimenter-subject anonymity on prosocial behavior in laboratory experiments is hard to interpret as differences in experimental procedures and games within and across studies make it difficult to derive a coherent overall conclusion from the results. In this paper we move a step forward and develop a novel experimental procedure which is transparent and self-explanatory and allows for a clean ceteris-paribus variation of anonymity in several games. Using these procedures we investigate whether the presence of double anonymity leads to a systematic change in prosocial behavior in three of the most often used laboratory experiments to measure social preferences. We find that the variation of anonymity does not significantly affect behavior in the dictator game, the ultimatum game, or the trust game. In addition, we observe that the behavior of our participants replicates previously reported results in experiments using the same games.

We think that our results are interesting for at least two reasons. First, our findings show that observed prosocial behavior in laboratory experiments cannot be denounced as being just an artifact of the lack of experimenter-subject anonymity. This is important as the empirical basis of the whole literature on social preferences mostly relies on laboratory results. Second, our findings provide useful information for researchers using laboratory experiments. Ensuring experimenter-subject anonymity inevitably complicates procedures and severely limits the degrees of freedom in experimental design. Thus, knowing that the lack of experimenter-subject anonymity does not lead to a significant increase in (seemingly) prosocial behavior, clears the way for many interesting future studies. 


\section{References}

Ackert, L. F., A. B. Gillette, J. Martinez-Vazquez, and M. Rider (2009): "Risk Tolerance, Self-Interest, and Social Preferences," Georgia State University Experimental Economics Center Working Paper Series 2009-04.

Andreoni, J. (1990): "Impure Altruism and Donations to Public Goods: A Theory of Warm-Glow Giving?" Economic Journal, 100, 464-77.

(1995): "Warm-Glow versus Cold-Prickle: The Effects of Positive and Negative Framing on Cooperation in Experiments," The Quarterly Journal of Economics, 110, $1-21$.

Bardsley, N., R. Cubitt, G. Loomes, P. Moffatt, C. Starmer, and R. SugDEN (2010): Experimental economics: Rethinking the rules, Princeton University Press.

Bartling, B. And F. von Siemens (2010): "The Intensity of Incentives in Firms and Markets: Moral Hazard with Envious Agents," Labour Economics, 17, 598-607.

Belot, M., R. Duch, and L. Miller (2010): "Who should be called to the lab? A comprehensive comparison of students and non-students in classic experimental games," Discussion Papers 2010001, University of Oxford, Nuffield College.

Benabou, R. and J. Tirole (2006): "Incentives and Prosocial behavior," American Economic Review, 96, 1652-1678.

Berg, J., J. Dickhaut, and K. McCabe (1995): "Trust, Reciprocity, and Social History," Games and Economic Behavior, 10, 122-142.

Bohnet, I. And B. S. Frey (1999): "Social Distance and Other-Regarding Behavior in Dictator Games: Comment," American Economic Review, 89, 335-339.

Bolton, G. E. And A. Ockenfels (2000): "ERC: A Theory of Equity, Reciprocity, and Competition," American Economic Review, 90, 166-193.

Bolton, G. E. AND R. Zwick (1995): "Anonymity versus Punishment in Ultimatum Bargaining," Games and Economic Behavior, 10, 95-121.

Bolton, G. E., R. Zwick, And E. Katok (1998): "Dictator game giving: Rules of fairness versus acts of kindness," International Journal of Game Theory, 27, 269-299.

Bowles, S. AND S.-H. Hwang (2008): "Social preferences and public economics: Mechanism design when social preferences depend on incentives," Journal of Public Economics, 92, 1811 - 1820.

Brown, M., A. Falk, And E. Fehr (2004): "Relational Contracts and the Nature of Market Interactions," Econometrica, 72, 747-780. 
Burks, S., J. Carpenter, and L. Goette (2009): "Performance pay and worker cooperation: Evidence from an artefactual field experiment," Journal of Economic Behavior \&5 Organization, 70, 458-469.

Camerer, C. F. (2003): Behavioral Game Theory: Experiments in Strategic Interaction (The Roundtable Series in Behavioral Economics), Princeton University Press.

Cameron, L. A. (1999): "Raising the Stakes in the Ultimatum Game: Experimental Evidence from Indonesia," Economic Inquiry, 37, 47-59.

Carpenter, J., E. Verhoogen, And S. Burks (2005): "The effect of stakes in distribution experiments," Economics Letters, 86, 393-398.

Charness, G. And M. Dufwenberg (2006): "Promises and Partnership," Econometrica, 74, 1579-1601.

Charness, G. And M. Rabin (2002): "Understanding Social Preferences With Simple Tests," The Quarterly Journal of Economics, 117, 817-869.

Cherry, T. L., P. Frykblom, and J. F. Shogren (2002): "Hardnose the Dictator," American Economic Review, 92, 1218-1221.

Cleave, B. L., N. Nikiforakis, And R. Slonim (2010): "Is There Selection Bias in Laboratory Experiments?" Department of Economics - Working Papers Series 1106, The University of Melbourne.

Cooper, D. J. And J. H. Kagel (forthcoming): "Other Regarding Preferences: A Selective Survey of Experimental Results," in The Handbook of Experimental Economics, ed. by J. H. Kagel and A. Roth.

Cox, J. C. And C. A. Deck (2005): "On the Nature of Reciprocal Motives," Economic Inquiry, 43, 623-635.

Croson, R. And S. Gaechter (2010): "The science of experimental economics," Journal of Economic Behavior $\&$ Organization, 73, 122-131.

Dohmen, T., A. Falk, D. Huffman, and U. Sunde (2008): "Representative Trust And Reciprocity: Prevalence And Determinants," Economic Inquiry, 46, 84-90.

DufwenberG, M. And G. Kirchsteiger (2004): "A theory of sequential reciprocity," Games and Economic Behavior, 47, 268-298.

Egas, M. AND A. RiedL (2008): "The economics of altruistic punishment and the maintenance of cooperation," Proceedings of the Royal Society - Biological Sciences, $871-878$.

Ellingsen, T. And M. Johannesson (2007): "Paying Respect," Journal of Economic Perspectives, 21, 135-150. 
(2008): "Pride and Prejudice: The Human Side of Incentive Theory," American Economic Review, 98, 990-1008.

Falk, A., E. Fehr, And C. Zehnder (2006): "Fairness Perceptions and Reservation Wages - The Behavioral Effects of Minimum Wage Laws," Quarterly Journal of Economics, 121, 1347-1381.

FAlK, A. AND U. FischBacher (2006): "A theory of reciprocity," Games and Economic Behavior, 54, 293-315.

Falk, A. And J. Heckman (2009): "Lab Experiments Are a Major Source of Knowledge in the Social Sciences," Science, 326, 535-538.

Falk, A., S. Meier, And C. Zehnder (2010): "Do Lab Experiments Misrepresent Social Preferences? The case of self-selected student samples," Working paper, University of Lausanne.

Fehr, E., U. Fischbacher, And E. Tougareva (2002): "Do High Stakes and Competition Undermine Fairness? Evidence from Russia," IEW - Working Papers iewwp120, Institute for Empirical Research in Economics - IEW.

Fehr, E. And S. Gaechter (2000): "Cooperation and Punishment in Public Goods Experiments," American Economic Review, 90, 980-994.

Fehr, E., S. Gaechter, And G. Kirchsteiger (1997): "Reciprocity as a Contract Enforcement Device: Experimental Evidence," Econometrica, 65, pp. 833-860.

Fehr, E., O. Hart, And C. Zehnder (2011): "Contracts as Reference Points Experimental Evidence," American Economic Review, 101, 493-525.

Fehr, E., A. Klein, And K. M. Schmidt (2007): "Fairness and Contract Design," Econometrica, 75, 121-154.

FeHr, E. AND J. A. List (2004): "The Hidden Costs and Returns of Incentives - Trust and Trustworthiness among CEOs," Journal of the European Economic Association, 2, 743-71.

Fehr, E. And K. Schmidt (2003): "Theories of Fairness and Reciprocity - Evidence and Economic Application," in Advances in Economics and Econometrics 8th World Congress, Econometric Society Monographs, ed. by M. Dewatripont, L. P. Hansen, and S. J. Turnovsky, Cambridge: Cambridge University Press, 208-57.

Fehr, E. And K. M. Schmidt (1999): "A Theory Of Fairness, Competition, And Cooperation," The Quarterly Journal of Economics, 114, 817-868.

Forsythe, R., J. L. Horowitz, N. E. Savin, And M. Sefton (1994): "Fairness in Simple Bargaining Experiments," Games and Economic Behavior, 6, 347-369. 
Glaeser, E. L., D. I. Laibson, J. A. Scheinkman, and C. L. Soutter (2000): "Measuring Trust," The Quarterly Journal of Economics, 115, 811-846.

Goeree, J. K. And C. A. Holt (2000): "Asymmetric inequality aversion and noisy behavior in alternating-offer bargaining games," European Economic Review, 44, 1079-1089.

Gueth, W., R. Schmittberger, and B. Schwarze (1982): "An experimental analysis of ultimatum bargaining," Journal of Economic Behavior $\mathscr{E}$ Organization, $3,367-388$.

Henrich, J., S. Heine, and A. Norenzayan (2010): "The weirdest people in the world," Behavioral and Brain Sciences, 33, 61-83.

Hoffman, E., K. McCabe, K. Shachat, and V. L. Smith (1994): "Preferences, Property Rights, and Anonymity in Bargaining Games," Games and Economic Behavior, 7, 346-380.

Hoffman, E., K. McCabe, And V. L. Smith (1996): "Social Distance and OtherRegarding Behavior in Dictator Games," American Economic Review, 86, 653-60.

Kosfeld, M., A. Okada, And A. Riedl (2009): "Institution Formation in Public Goods Games," American Economic Review, 99, 1335-55.

Laury, S. K., J. M. Walker, and A. W. Williams (1995): "Anonymity and the voluntary provision of public goods," Journal of Economic Behavior E3 Organization, $27,365-380$.

Lazear, E., U. Malmendier, and R. Weber (2011): "Sorting in Experiments with Application to Social Preferences," Working paper.

Levine, D. K. (1998): "Modeling Altruism and Spitefulness in Experiment," Review of Economic Dynamics, 1, 593-622.

Levitt, S. D. And J. A. List (2007): "What Do Laboratory Experiments Measuring Social Preferences Reveal About the Real World?" Journal of Economic Perspectives, 21, 153-174.

List, J. A. (2009): "Social Preferences: Some Thoughts from the Field," Annual Review of Economics, 1, 1:21.1-21.20.

List, J. A., R. P. Berrens, A. K. Bohara, and J. Kerkvliet (2004): "Examining the Role of Social Isolation on Stated Preferences," American Economic Review, 94, 741-752.

Loewenstein, G. (1999): "Experimental Economics from the Vantage-Point of Behavioural Economics," Economic Journal, 109, F23-34. 
MacLeod, W. B. (2007): "Can Contract Theory Explain Social Preferences?" American Economic Review, 97, 187-192.

MacLeod, W. B. And J. M. Malcomson (1998): "Motivation and Markets," American Economic Review, 88, 388-411.

Masclet, D. And M.-C. Villeval (2008): "Punishment, inequality, and welfare: a public good experiment," Social Choice and Welfare, 31, 475-502.

Rabin, M. (1993): "Incorporating Fairness into Game Theory and Economics," American Economic Review, 83, 1281-1302.

Roth, A. (1995): Bargaining experiments, Princeton University Press, New Jersey, chap. Roth, A. E., 1995, , in: J. H. Kagel and A. E. Roth, eds., The Handbook of Experimental Economics (Princeton University Press, New Jersey).

Schmidt, C. And R. Zultan (2005): "The Uncontrolled Social Utility Hypothesis Revisited," Economics Bulletin, 3, 1-7.

Slonim, R. And A. E. Roth (1998): "Learning in High Stakes Ultimatum Games: An Experiment in the Slovak Republic," Econometrica, 66, 569-596.

Tyran, J.-R. And R. SAusgruber (2006): "A little fairness may induce a lot of redistribution in democracy," European Economic Review, 50, 469-485. 
Table 1: Comparison of first mover transfers

\begin{tabular}{llccccc}
\hline \hline \multirow{2}{*}{ Experiment } & Anonymity & N(pairs) & Mean & Median & $\begin{array}{c}\text { Selfish } \\
\text { (in \%) }\end{array}$ & $\begin{array}{c}\text { Fair/Trust } \\
\text { (in \%) }\end{array}$ \\
\hline \multirow{2}{*}{ Dictator } & Single & 49 & 3.9 & 4 & 36.7 & 12.2 \\
& Double & 54 & 3.3 & 2 & 42.6 & 14.8 \\
\multirow{4}{*}{ Trustimatum } & Single & 53 & 8.6 & 8 & 0 & 37.7 \\
& Double & 47 & 8.3 & 8 & 0 & 38.3 \\
& Single & 45 & 6.3 & 7 & 17.8 & 35.6 \\
\hline \hline
\end{tabular}

Notes: The endowment of first movers in the dictator and the ultimatum game is CHF 20. In the trust game both players get and endowment of CHF 10. The last two columns report the relative frequencies of decisions which are compatible with the self-interest equilibrium (selfish) and the desire to reach an efficient equal split of payoffs (Fair/Trust), respectively (see Footnote 14 for details). 
Table 2: Comparison of first and second mover transfers across treatments

\begin{tabular}{lcccc}
\hline \hline Dependent variable & DG $(\mathrm{fm})$ & $\mathrm{UG}(\mathrm{fm})$ & $\mathrm{TG}(\mathrm{fm})$ & TG (sm) \\
& $(1)$ & $(2)$ & $(3)$ & $(4)$ \\
\hline \multirow{2}{*}{ Double anonymity } & -0.659 & -0.226 & 0.0541 & -1.014 \\
& $(0.736)$ & $(0.436)$ & $(0.789)$ & $(1.067)$ \\
First mover transfer & & & $1.081^{* * *}$ \\
& & & & $(0.120)$ \\
Constant & $3.918^{* * *}$ & $8.566^{* * *}$ & $6.267^{* * *}$ & -0.194 \\
& $(0.511)$ & $(0.316)$ & $(0.567)$ & $(0.731)$ \\
\hline \multirow{3}{*}{ Observations } & 103 & 100 & & 98 \\
$\mathrm{R}^{2}$ & 0.008 & 0.003 & 0.000 & 0.393 \\
\hline \hline
\end{tabular}

Notes: OLS estimations with robust standard errors in parentheses. The dependent variables in columns (1) to (3) are the first mover transfers in the dictator game (DG), ultimatum game (UG) and trust game (TG). The dependent variable in column (4) is second mover repayments in the trust game. $* * *$ indicates significance at the 1-percent level, ${ }^{* *}$ indicates significance at the 5 -percent level, and $*$ indicates significance at the 10-percent level. 


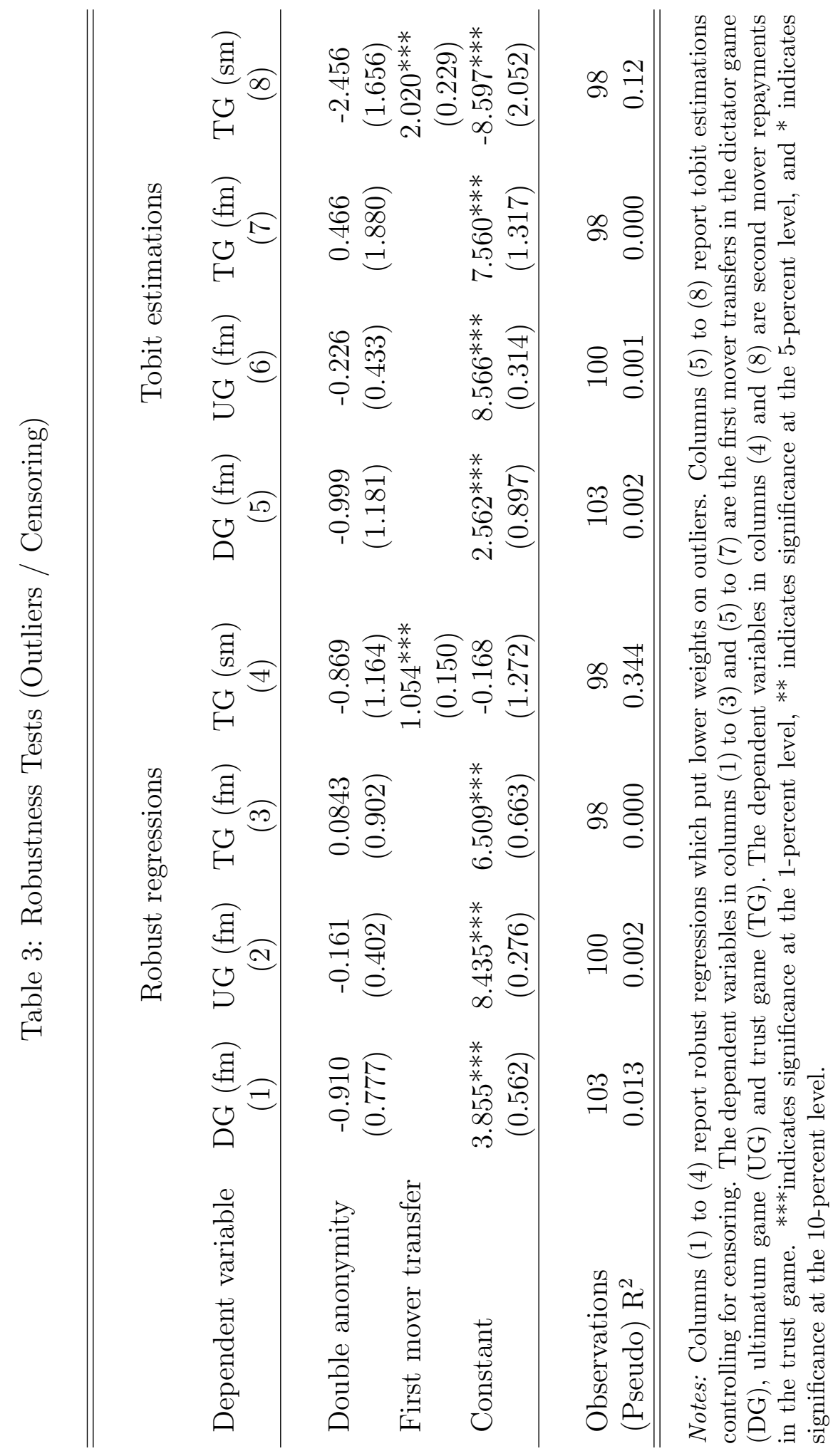


Figure 1: Overview of decisions
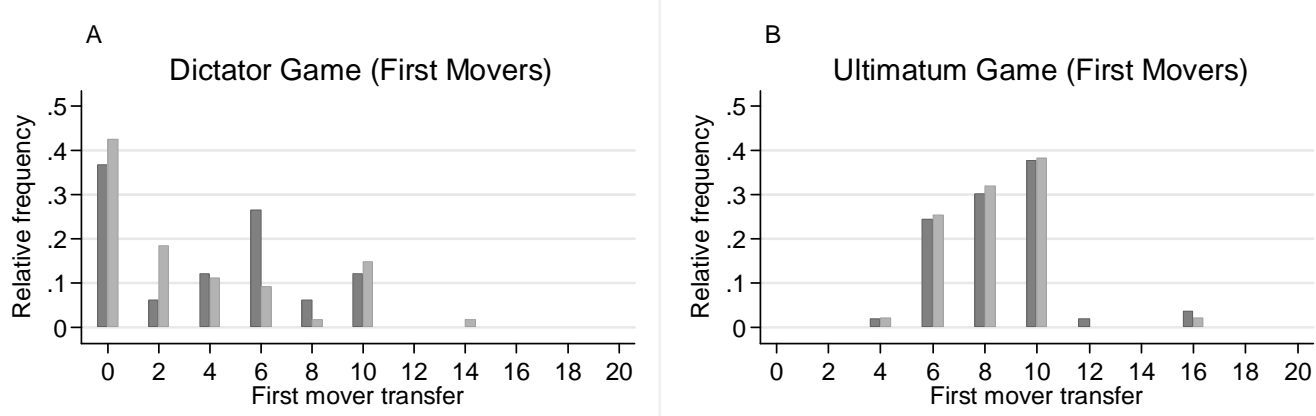

C

Trust Game (First Movers)

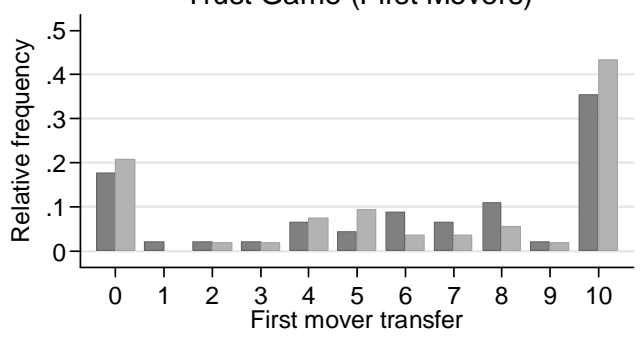

D

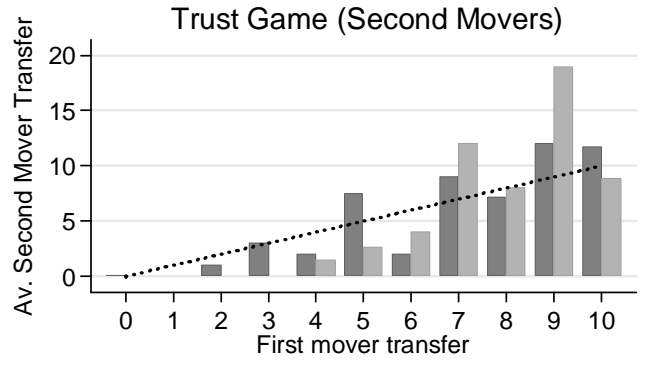

single-anonymous

double-anonymous

Notes: Panels A to $\mathrm{C}$ show histograms of first mover decisions in the dictator, ultimatum, and trust games. Panel D displays average second mover repayments conditional on received first mover transfers in the trust game. The dotted line represents the break-even frontier for first mover investments (i.e., average second mover repayment $=$ first mover transfer). 


\section{A Complete Instructions for First Movers in the Ultimatum Game}

The following is an English translation of our originally German instructions. The German instructions are available from the authors on request. We reproduce the instructions for Participant A in the ultimatum game. The instructions for Participant $\mathrm{B}$ and other games are very similar. We make explicit which parts differ between singleand double anonymous conditions.

\section{General Instructions for Participant A}

Thank you very much for your participation in this scientific study. Please read the following explanations carefully. If you have questions, please raise your hand and the experimenter will come to you.

This set of instructions is exclusively for your personal use. During the experiment any form of communication with other participants is strictly prohibited. Non-observance of this rule results in exclusion from the experiment and all payments.

You receive a fixed amount of 10 Francs for the participation in this experiment. In addition, you have the opportunity to earn more money which is added to this fixed amount. How much additional money you earn depends on your decision and the decision of another participant in the experiment.

At the end of the experiment you receive the amount of money earned in the experiment plus the fixed amount of 10 Francs in cash.

In the following we provide you with a detailed explanation of the procedures of the experiment.

\section{The Experiment}

There are two types of participants in this experiment: Participants A and Participants B. Each Participant A is paired with a Participant B.

\section{You are in the role of Participant A for the whole duration of the study.}

All participants in the role of Participant A are seated on the same side of the room as you. People in the role of Participant B are seated on the other side of the room.

The Participant B with whom you will be paired in the experiment will be determined randomly during the experiment. You will never be informed about the identity of the Participant B with whom you are paired and Participant B will never be informed about your identity.

On the following page we describe in detail the decisions which you can make during the upcoming experiment. 


\section{The Decision Situation}

\section{The starting point}

Both Participant A and Participant B have to make a decision in this experiment. Participant A makes his decision first. As Participant A you receive an initial endowment of 20 Francs. Participant B does not receive an endowment.

Phase 1: Your decision

As Participant A you have to decide how much of your endowment you would like to transfer to the Participant B who has been assigned to you. You can transfer any even-numbered integer amount between 0 and 20 Francs. In other words you can transfer 0 Francs, 2 Francs, 4 Francs, 6 Francs, ..., up to 20 Francs.

\section{Phase 2: Participant B's decision}

After you have made your transfer decision, Participant B can make his decision. Participant B has the possibility to accept your transfer or to reject your transfer. If Participant B decides to accept the transfer, he or she receives the transferred money, and you keep the rest of your endowment. If he or she decides to reject the transfer you and Participant $\mathrm{B}$ receive no money.

\section{Phase 3: Determination of incomes}

After Participant B has made his or her decision, all decisions have been made and your income and Participant B's income can be calculated.

\section{Your income}

If Participant B accepts your transfer, your income is determined as follows: You receive your endowment of 20 Francs minus your transfer to Participant B.

If Participant B rejects your transfer, your income is zero.

$$
\begin{array}{ll}
\text { If } B \text { accepts: } & \text { Your income }=\text { Endowment }- \text { Transfer to B } \\
\text { If B rejects: } & \text { Your income }=0
\end{array}
$$

Participant B's income

If Participant B accepts your transfer, his or her income is equal to your transfer to B. If Participant B rejects your transfer, his or her income is zero.

$\begin{array}{ll}\text { If } B \text { accepts: } & \text { Income of } B=\text { Transfer to } B \\ \text { If } B \text { rejects: } & \text { Income of } B=0\end{array}$




\section{Procedural Details}

At the beginning of the experiment a participant has been selected to assist the experimenter during the experiment and to supervise that all steps of the experiment follow the predetermined rules stated in these instructions. This participant is henceforth called the "helper".

Each participant in the experiment has randomly drawn an envelope in the beginning. Participants who have drawn a red envelope are in the role of Participant A, participants who have drawn a blue envelope are in the role of Participant B. Your red envelope contains two small cards with your anonymous three digit identity number. Since you have drawn your envelope randomly no other participant knows your anonymous identity number. Please do not yet open your red envelope. The experimenter will later ask you to open the envelope.

\section{Participant A's Decision}

You can indicate your decision on a decision sheet that will be distributed after all participants have completed reading the instructions. On the decision sheet you indicate the amount of money that you are willing to transfer to Participant B by checking the corresponding box. When you have made your decision, please put the decision sheet into the yellow decision envelope which you find at your workplace. In addition, please put one of your small identity cards contained in your red envelope into the small white envelope which you also find at your workplace. Then, please seal the small white envelope and also put it into the yellow envelope. Finally, please close the yellow envelope with the removable fastener, so that nothing can fall out of the envelope.

When all Participants A have made their decisions, the helper will collect all yellow envelopes in a box. After the helper has carefully shuffled the envelopes, each Participant $\mathrm{B}$ will draw a yellow envelope out of the box. On instruction of the experimenter participants $B$ will then remove the decision sheet with the decision of Participant A from the yellow envelope. When removing the decision sheet, Participants B will be instructed to make sure that the small white envelope containing the identity number of Participant A remains in the yellow envelope. The helper will ensure that no Participant B ever open a white envelope.

\section{Participant B's Decision}

Participant B can now see how much you as Participant A have transferred to him. After inspecting the decision sheet, Participant B indicates on the decision sheet whether he would like to accept or reject your transfer. Then, Participant B returns the decision sheet into the yellow envelope, puts one of his or her own small identity cards into another small white envelope, seals the white envelope and adds it to the rest of the material in the yellow envelope. Finally, participant B reattaches the removable fastener and closes the yellow envelope, so that nothing can fall out.

After all Participants B have made their decision, the helper again collects all yellow 
envelopes in the box. Subsequently, the helper hands over the box to the experimenter. The experimenter takes the box to a small room adjacent to the experiment room and calculates the monetary payoffs of participants based on the decisions contained in the yellow envelopes. The helper stays in the lecture room during this time.

***The following paragraphs were only included in the single-anonymity condition***

\section{Calculation of Payoffs}

Each yellow envelope contains the decision sheet containing the decisions of Participant A and Participant B. This allows the experimenter to calculate the payoff of Participants A and B. As soon as the payoffs are calculated the experimenter puts the money earned by Participant A (including the fixed amount of 10 Francs for participation) in a white payout envelope and marks the envelope with the identity number of Player A. The money earned by Participant B (including the fixed amount of 10 Francs for participation) is being put in another white payout envelope which is marked with the identity number of Participant B. In addition to preparing the payout envelopes, the experimenter also prepares a personal receipt for each participant. The receipt contains the identity number of the participant and indicates the earned amount of money. When the participant collects the money, he has to add his name on the form and sign it.

\section{Payout Procedure}

As soon as all payout envelopes have been prepared, the experimenter places the envelopes ordered by identity number on a table outside of the lecture room. All envelopes are stuffed, so that it is impossible to see how much money is in there from the outside. The experimenter then goes to the payout table and participants can pick up their money one-on-one. Each participant receives his payout envelope in privacy. When picking up his or her envelope every participant hands over the second small identity card to the experimenter. Then the experimenter will ask the participant to add his or her name on the receipt and to sign it. As soon as all participants have received their envelope the experiment is over.

If you have any questions regarding the procedures of this experiment, please raise your hand. The experimenter will then come to your workplace and answer your question in privacy.

***The following paragraphs were only included in the double-anonymity condition***

\section{Calculation of Payoffs}

Each yellow envelope contains the decision sheet containing the decisions of Participant A and Participant B. This allows the experimenter to calculate the payoff of 
Participants A and B. As soon as the payoffs are calculated the experimenter puts the money earned by Participant A (including the fixed amount of 10 Francs for participation) in a white payout envelope and marks the envelope with the identity number of Player A. The money earned by Participant B (including the fixed amount of 10 Francs for participation) is being put in another white payout envelope which is marked with the identity number of Participant B. The experimenter does not know which identity number belongs to which participant.

\section{Payout Procedure}

As soon as all payout envelopes have been prepared, the experimenter places the envelopes ordered by identity number on a table outside of the lecture room. Then the experimenter returns to the lecture room. All envelopes are stuffed, so that it is impossible to see how much money is in there from the outside. The helper then goes to the payout table and participants can pick up their money one-on-one. Each participant receives his payout envelope in privacy. When picking up his or her envelope every participant hands over the second small identity card to the helper, so that the helper can ensure that the participant takes the correct envelope. As soon as all participants have received their envelope the experiment is over.

If you have any questions regarding the procedures of this experiment, please raise your hand. The experimenter will then come to your workplace and answer your question in privacy. 


\section{Control Questions}

Please answer the following control questions. Please write down how you calculate the payoffs. If you have questions, please raise your hand, to call the experimenter. Once you have completed all questions, please raise your hand. The experimenter will then join you at your work place to control your answers.

The purpose of these questions is to check whether all participants completely understand the rules of the experiment. Wrong answers do not have any consequences for your monetary payoffs in the experiment.

Question 1:

You transfer 10 Francs to Particpant B and he or she accepts your transfer.

Your income:

Particpant B's income:

Question 2:

You transfer 0 Francs to Particpant $\mathrm{B}$ and he or she rejects.

Your income:

Particpant B's income:

Question 3:

You transfer 2 Francs to Particpant B and he or she accepts your transfer.

Your income:

Particpant B's income:

Question 4:

You transfer 8 Francs to Particpant B and he or she rejects.

Your income:

Particpant B's income: 


\section{Decision Sheet for Participant A and Participant B}

Participant A: Please check the box corresponding to your transfer decision in the first column.

Participant B: Please use the right-hand side to indicate whether you would like to accept or reject the transfer by checking the corresponding box.

\begin{tabular}{|c|c|}
\hline \multicolumn{2}{|c|}{ Participant A's Decision } \\
\hline $\begin{array}{c}\text { Please check a } \\
\text { box! }\end{array}$ & $\begin{array}{c}\text { Participant A's } \\
\text { transfer }\end{array}$ \\
\hline$\square$ & 0 \\
\hline$\square$ & 2 \\
\hline$\square$ & 4 \\
\hline$\square$ & 6 \\
\hline$\square$ & 8 \\
\hline$\square$ & 10 \\
\hline$\square$ & 12 \\
\hline$\square$ & 14 \\
\hline$\square$ & 16 \\
\hline$\square$ & 18 \\
\hline$\square$ & 20 \\
\hline
\end{tabular}

\begin{tabular}{|c|}
\hline Participant B's Decision \\
\hline I accept the transfer $\square$ \\
I reject the transfer $\square$ \\
\hline
\end{tabular}

